\title{
Seeking a Balance: Helping Pre-Service Teachers Develop Positive Attitudes towards Mathematics as They Develop Competency
}

\author{
Chris Hurst, Audrey Cooke \\ School of Education, Curtin University, Perth, Australia \\ Email: c.hurst@curtin.edu.au
}

Received 16 November 2013; revised 21 December 2013; accepted 31 December 2013

Copyright (C) 2014 by authors and Scientific Research Publishing Inc.

This work is licensed under the Creative Commons Attribution International License (CC BY). http://creativecommons.org/licenses/by/4.0/

(c) (i) Open Access

\section{Abstract}

Mathematical competence of teachers continues to be an issue of great interest to mathematics educators within tertiary institutions and it is often thought of simultaneously with the notion of mathematics anxiety. While there has been considerable recent research into the latter, no clear conclusions have been able to be drawn about many aspects of the phenomenon and how it is linked to mathematical competence. Most recently, international studies have highlighted notable differences in the standards of teacher preparation in different countries and in Australia new standards for accreditation of teacher education programs have been drafted. This paper reports on a part of on-going research into mathematics anxiety and competence of pre-service teachers. It uses two small samples of pre-service teachers from different cohorts of a Bachelor of Education course and attempts to identify factors that may help develop positive attitudes towards mathematics as they seek to develop their competency in mathematics. In addition, as a response to greater reported levels of anxiety regarding cognitive and knowledge traits, the paper identifies targeted professional learning and social constructivist teaching as key factors as well as the need to identify personal knowledge of mathematics as a prelude to seeking to become more competent.

\section{Keywords}

Mathematics Education; Pre-Service Teacher; Competency; Attitudes 


\section{Introduction}

The issue of mathematical competence of experienced, graduate and pre-service primary and early childhood teachers has long been of concern. Findings from the recent Teacher Education and Development Study-Mathematics (TEDS-M) by the International Association for the Evaluation of Educational Achievement (IEA) indicated that there is considerable variation in standards of mathematics competence in pre-service teachers. The study also revealed some tension regarding the mathematical content knowledge requirements of pre-service teachers. Specifically, it found that there "...seems to be a cultural norm in some countries... that teachers who are expected to teach in primary - and especially the lower-primary - grades need little in the way of mathematics content beyond that included in the school curriculum" [1]. Recently, the Australian Institute for Teaching and School Leadership (AITSL) put forward a set of standards for entry into teacher education programs which reflect such concerns and can be seen as an attempt to ensure that graduate teachers are more competent in mathematics. Specifically, AITSL stated the following:

1) All entrants to initial teacher education will successfully demonstrate their capacity to engage effectively with a rigorous higher education program and to carry out the intellectual demands of teaching itself. To achieve this, it is expected that applicants' levels of personal literacy and numeracy should be broadly equivalent to those of the top 30 per cent of the population.

2) Providers who select students who do not meet the requirements in 1) above must establish satisfactory additional arrangements to ensure that all students are supported to achieve the required standard before graduation [2].

While there is no specification as to exactly what the "top 30 percent" would be with regard to numeracy, the AITSL statement appears to reflect a desire to improve personal mathematics competence of pre-service teachers.

Associated with the issue of mathematical competence is that of confidence and/or anxiety about mathematics. This has also been of concern to mathematics educators with a number of reasons, perhaps the most notable being that it is acknowledged that teachers can pass on their anxiety to students [3]. Recent research [4] concluded that it was difficult to draw clear links between measures of mathematics anxiety and mathematical competence of pre-service teachers, that is, that results from a questionnaire of mathematics anxiety cannot be used to accurately predict levels of competence. Indeed, some pre-service teachers exhibited high levels of confidence and low anxiety yet did not pass a mathematics competency test, while some others exhibiting lower confidence and higher anxiety levels did well on the competency test. Hence, it appears that mathematics anxiety may be present in a number of pre-service teachers regardless of their levels of competence. Conversely, some pre-service teachers may exhibit low levels of mathematics anxiety, yet not necessarily be competent in mathematics. Perhaps as Cooke and Sparrow point out, "many of these pre-service teachers [may be] unaware of their lack of deeper mathematical knowledge" [5] and reported low levels of anxiety as a consequence.

This notion of knowledge awareness may be worth exploring further with respect to reported mathematics anxiety levels of pre-service teachers. A number of existing models depict the levels of awareness people may have about their own mathematical competence. This is often depicted in a hierarchical model akin to Table 1.

It is suggested that pre-service teachers who report low levels of anxiety towards mathematics may do so because of their own "unconscious incompetence" regarding their mathematical knowledge and that their reported anxiety level may well increase once they become more aware of their own shortcomings.

Michigan State University's MSU Today website [2012] cited Schwille, one of the TEDS-M researchers, who noted that there are certainly some "born teachers" but not sufficient to meet demands, so the onus is on universities to prepare them for their future work [6]. Given the current AITSL entry requirements, this poses somewhat of a dilemma in that prospective entrants to teacher education programs may well be akin to the "born teachers". They may see teaching as their perfect career and have an almost missionary zeal to pursue it, yet they

\begin{tabular}{cc} 
Table 1. Hierarchical representation of awareness of knowledge. \\
\hline Level 4 & Unconscious competence \\
Level 3 & Conscious competence \\
Level 2 & Conscious incompetence \\
Level 1 & Unconscious incompetence \\
\hline
\end{tabular}


may not have the required levels of competence to cope with their training. Once they progress from a level of "unconscious incompetence" to one of "conscious incompetence", it is likely that their levels of anxiety will rise. Hence, teacher education institutions need to strike a balance between the required level of mathematical competence and associated pedagogies and the development of confidence and lessening of anxiety levels about mathematics.

\section{Research Question}

This paper reports on continuing research into the levels of competence and anxiety of pre-service teachers at one Australian university. It explores links between the two phenomena and seeks to understand the relationships between them. One purpose of the research is to inform the comprehensive course re-view of the current Bachelor of Education course with regard to mathematics education and preparation of competent and confident graduate teachers. To date, the research has used a three part questionnaire developed by Cavanagh \& Sparrow [7] and calibrated for use with pre-service teachers by Cooke, Cavanagh, Hurst, and Sparrow [8] to identify anxiety traits in pre-service teachers for three different situations - doing mathematics with others, taking a test in mathematics, and thinking about teaching mathematics. Findings so far are that pre-service teachers are most concerned about their levels of knowledge and understanding of mathematics concepts and this anxiety is most manifest when working with others on mathematics or thinking about teaching it. It is suggested that the high levels of reported concern related to somatic indicators when doing mathematics with others could be in response to participants' perceived lack of knowledge and concern about how others might view them [4]. In other words, some of the pre-service teachers may be displaying "conscious incompetence" as de-scribed earlier. This paper focuses on two small groups of pre-service teachers and attempts to answer the following re-search question:

What factors can lessen the anxiety levels of pre-service teachers towards mathematics as they attempt to become more competent to teach it?

\section{Methodology}

Students who participated in the study completed a three part questionnaire described earlier. It identified levels of anxiety traits about three situations involving mathematics and was based on a four point Likert scale. As well, pre-service teachers in the first year primary cohort were asked to sit a mathematics competency test prior to completing their first mathematics education unit. Those who sat the test were invited to complete a follow up questionnaire to determine if there were any notable changes in their feelings about mathematics. Fourteen students responded and they form the first of the two groups about which this paper reports. The second group consisted of four third year pre-service teachers in the early childhood course. These students had reported high levels of anxiety on the three part questionnaire and attended optional professional learning workshops. They then participated in semi-structured interviews to ascertain any changes in their feelings about mathematics.

\section{Results and Discussion}

\subsection{Group One-Portion of First Year Primary Cohort ( $n=14$ )}

All of the students in this group passed the mathematics competency test prior to completing the first mathematics education unit. Their responses to the three part questionnaire were positive with most reporting very low or low levels of anxiety and two reporting moderate levels of anxiety. The three part questionnaire contained a total of 66 statements to which participants could respond. Anxiety levels were considered to be low if a total of 12 or less negative responses were reported as this is less than $20 \%$ of the possible total. The participants whose anxiety levels were deemed low or very low reported between 0 and 12 negative responses. The two participants who reported moderate anxiety reported 18 and 20 negative responses respectively. The follow up questionnaire asked participants to respond to how they felt after their first year of study about the three situational aspects of mathematics covered in the original three part questionnaire that is doing mathematics with others, taking a test in mathematics and thinking about teaching mathematics. Their responses are summarized in Table 2.

It is evident that all fourteen participants reported feeling at least "the same" about the three situations with none reporting worse feelings. The greatest change in feelings was apparent in the "thinking about teaching ma- 
Table 2. First year cohort: summary of changes in feelings after first year of course.

\begin{tabular}{cccc}
\hline & \multicolumn{3}{c}{ Changes in feelings } \\
\hline & Much better & Better & Same \\
\hline Working with others on mathematics & 1 & 10 & 3 \\
Taking a test in mathematics & 0 & 6 & 8 \\
Thinking about teaching mathematics & 6 & 6 & 2 \\
\hline
\end{tabular}

thematics" situation whilst the smallest change was noted for the test situation. Reasons offered for such changes all acknowledged the value of the professional learning, in the form of the first mathematics education unit. Participants were quite glowing in their praise noting the value of what they learned from the unit and also the constructivist style with which the unit was taught. A summary of what the participants said they gained from the unit is included here:

- Greater confidence to work with others and teach mathematics;

- Better understanding of mathematics concepts;

- Strong foundation for teaching mathematics having been equipped with strategies for doing so;

- Knowledge of how to help children construct their own mathematical understanding;

- Greater enthusiasm for teaching mathematics in innovative and exciting ways [4].

\subsection{Group Two-Portion of Third Year Early Childhood Cohort $(\mathrm{n}=4)$}

Following the administration of the three part questionnaire, it was evident that a number of pre-service teachers, particularly in the Early Childhood course, reported high and very high levels of anxiety. Pre-service teachers in all cohorts had been advised that they needed to pass the mathematics competency test before graduating and a number of them had avoided sitting for test, and still had not sat the test by mid-way through their third year of the four year course. In order to help them prepare for the test, they were offered the opportunity to participate in a series of professional learning workshops designed to further their knowledge of key mathematics concepts. The four pre-service teachers who responded to a request for an interview all reported high or very high levels of anxiety on the three part questionnaire, with $28,28,33$ and 58 negative responses respectively out of a possible 66. The interviews were conducted in order to probe for some explanation for such high levels of anxiety. Participants were asked to respond to questions about the three situations for mathematics anxiety and to reflect on the somatic, attitude, cognitive and knowledge traits as reflected in the three part questionnaire. It was also hoped to be able to consider the interview responses alongside the questionnaire responses obtained from Group One above. Pseudonyms are used for the participants involved.

\subsubsection{Student Lisa}

Lisa recorded 28 negative responses out of a possible 66. More negative responses were recorded for the test situation than the other two, as well as in relation to the cognitive and knowledge traits across all three situations. Lisa described her mathematical competence in terms of being "good at primary school but doesn't get concepts like algebra because she hasn't done enough of it" (Interview Lisa). She feels that she basically doesn't have sufficient knowledge and that she "brushed over everything" when she was in high school. Her anxiety level in-creased when she failed the mathematics competency test at her first attempt. She is not frightened of mathematics per se but only when her lack of knowledge comes to the fore. "If I know it, I feel very confident; it's just the stuff I don't know... I quite like it when I know what I'm doing" (Interview, Lisa). This was manifest in Lisa's concern at the prospect of having to teach upper primary classes where topics such as algebra might need to be taught. Lisa felt that the professional learning workshops were of considerable value, that she knows more about mathematics than she did previously and that mathematics "makes more sense" as a result. In her words, "they helped me understand why things are like they are, rather than they are [her emphasis] like they are" (Interview, Lisa). As well, she noted that the workshops ex-posed her lack of knowledge- -I learnt things that I didn't know but didn't think I needed to know... like, I didn't think there was that to know" (Interview, Lisa). The workshops also helped Lisa to work through aspects of an on-line study plan designed to remediate areas of weakness. 
Lisa noted that her anxiety levels would likely reduce when she eventually passes the mathematics competency test but also when she gains more knowledge about mathematics in order to be able to teach "older" children in primary school. She acknowledged that the provision of the professional learning workshops was a move in the right direction as pre-service teachers had previously been largely left to their own devices in terms of preparing for and passing the competency test.

\subsubsection{Student Carrie}

Carrie recorded 28 negative responses on the three part questionnaire out of a total possible of 66 . The situations of greatest concern to her were thinking about teaching mathematics and doing maths with others. Also, the cognitive and knowledge traits had the highest number of negative responses across all situations. Carrie recently passed the mathematics competency test. She described herself as never having liked mathematics and that she tends to avoid it wherever possible. "I was always an average student... and I realized that if I did early childhood, I wouldn't need maths" (Interview, Carrie). One of her biggest concerns is a lack of knowledge as explained here- - "If I graduated and had to do relief in a Year Six classroom, then I'd definitely start to worry" (Interview, Carrie).

Carrie described the workshops as being of great value, that she generally feels better about mathematics and that she knows more mathematics than previously. She noted that the constructivist style in which the workshops were conducted was important. "It was really good to sit there with everyone else and see what they thought-everyone was willing to work together" (Interview, Carrie). As well, the relational way of teaching was appreciated in that she began to understand that "It's not a case of 'you either get it or you don't' but you can actually get better at it if you're given the tools to learn in the way that you learn best" (Interview, Carrie).

Carrie's comments about teaching style are supported by her description of how she first became anxious about mathematics. This was largely because lessons were textbook based with little interaction between teacher and student. "We'd go around the class and call out answers when it was our turn and I'd start to freak out because I wouldn't know what to say... I just always remember feeling scared to say 'I don't understand"” (Interview, Carrie). Carrie related an anecdote told to her by a tutor about a how female teacher walking into a classroom and feeling anxious about mathematics can instil the same feelings in her students. In order to be a better role model, she noted "it made me think that it's something I do need to work on and change" (Interview, Carrie).

\subsubsection{Student Anne}

Anne recorded 33 negative responses on the three part questionnaire out of a possible 66. She was most anxious about the test situation and similarly high levels of anxiety were recorded for the attitude, knowledge and cognitive traits across all three situations. Anne is a mature age student who completed Year Twelve mathematics and who has passed the mathematics competency test. She described herself as being "slightly above average" in mathematical ability yet her main concerns stem from the thought of having to teach older primary students. "I do have knowledge but I've forgotten it - I just need to re-ignite that knowledge again. That's my biggest fear about teaching upper primary" (Interview, Anne). In this, she noted that her anxiety level would increase when she had to teach something she had forgotten- "How can you teach somebody something if you don't understand it yourself?" (Interview, Anne).

Anne also acknowledged the value of the professional learning workshops though she said her knowledge had not increased much as she was starting from a higher knowledge base than others. She did however note that the style of teaching for the workshops and mathematics education units was very beneficial_- 'I've loved all of the activities we've done so far... working in groups. It's very different to what I'd been used to. I remember being at school and it was 'Here's the concept, here's your worksheet, off you go'. What I've experienced at university has been very different to my own earlier experiences" (Interview, Anne).

Anne reiterated that the need to "top up" her knowledge in order to teach older children was of concern to her as she had so far only taught early childhood classes. "That's probably causing some of my anxiety because I haven't been on a practicum yet where I've had older children" (Interview, Anne).

\subsubsection{Student Alice}

Alice could be described as having severe levels of anxiety. She recorded negative responses to 58 of the 66 statements on the three part questionnaire. She had not attempted the mathematics competency test at the time of 
the interview and described herself as a "terrible" mathematician. Her responses to all three situations regarding all anxiety traits were very negative and no particular trait or situation was prominent. Alice acknowledged that mathematics is important but she doesn't like it, "not even a little bit". When she is confronted with a mathematical situation, she noted "I just shut my brain down. I just say I don't know... I'd rather pull out the calculator or ask my husband" (Interview, Alice).

Alice attributed her high levels of anxiety to her lack of knowledge of basic skills, particularly basic number facts, and to a lack of effort on her part to learn them. "For some reason, I never have put in the effort... it was easier to say 'I don't know it' than to actually learn it" (Interview, Alice). She said that she liked her teachers but acknowledged that the professional learning workshops made her realize the things she did not know. "I knew it but I had forgotten it. The way that it was drilled into me as a child wasn't the only way-I had forgotten the ways it was supposed to be done" (Interview, Alice). She noted that the workshops were beneficial in that they highlighted for her that there are many ways of doing things. "The fact that I didn't have to stick to steps that I don't understand... that helped me... even to give that confidence to kids, to tell them that it's OK to do it the way you find easier or the way your brain works" (Interview, Alice).

Once she overcame her initial fears about the workshops, Al-ice said that she benefited from attending them. She felt that she learned some mathematics and that it was an important psycho-logical step for her to take to acknowledge that she needed to learn more. "I was frightened of coming across as not knowing and that really freaked me out... I was looking for any excuse not to go [to the second workshop] but none came out so I had to come... I knew I needed it so I had to push myself. I'm glad I did" (Interview, Alice).

\section{Conclusions}

Results from both groups in this study are similar and on the basis of them it has been possible to address the research question and identify a number of factors that may lessen the anxiety levels of pre-service teachers towards mathematics as they attempt to become more competent to teach it. It is noted that most of the following observations and conclusions are closely linked to one another.

First, both groups of pre-service teachers reported greater levels of anxiety with regard to the knowledge and cognitive traits. These traits are typically characterized by feelings of not knowing enough, being scared to make a mistake or not being confident to ask questions (knowledge) and feeling under threat, not being in control and forgetting things (cognitive). The high levels of anxiety usually manifest in situations where knowledge needs to be demonstrated. Second, both groups reported more positive attitudes towards mathematics following professional learning. For Group One (First Year cohort), this professional learning was in the form of their first Mathematics Education unit and for Group Two (Third Year cohort) it was a series of targeted professional learning workshops. Both groups reported gains in knowledge, understanding and confidence following the workshops. Third, in association with this, both groups acknowledged that the social constructivist teaching style used in the professional learning was very beneficial and was instrumental in the pre-service teachers developing more positive attitudes. Fourth, the professional learning served to highlight the knowledge that pre-service teachers did not realize they needed to have or had forgotten. In this, it brought into play the knowledge awareness hierarchy and in particular, the notion of "conscious incompetence" that needs to be addressed before competence can be seriously developed. Fifth, a number of the participants in Group Two openly spoke of their avoidance of mathematics as a result of their lack of knowledge. This had something of a "downward spiral" effect in that the avoidance factor meant that they were unable to address the issue of improving their competency levels. Finally, a number of important antecedents of mathematics anxiety were mentioned by participants in Group Two in particular in describing how earlier schooling practices had not been helpful in promoting a positive attitude towards mathematics.

\section{Implications and Recommendations}

The above conclusions have some important implications for the comprehensive course review that is currently in progress. The apparent value of the professional learning undergone by the pre-service teachers suggests that it might be prudent to postpone the necessity of having to pass a competency test until later in the Bachelor of Education course. Pre-service teachers have identified mathematical knowledge as a key factor in anxiety and it seems logical to provide them with ample opportunities to develop their own levels of competence before attempting to pass a competency test. Closely related to this is the social constructivist teaching style that partici- 
pants identified as a positive factor. It is strongly suggested here that all mathematics education units and professional learning should be conducted in this way. The professional learning workshops themselves were seen to be of considerable value and should be continued and expanded.

The related issues of knowledge and competence need to be approached with compassion. Results here suggest that when this is done, more positive attitudes towards mathematics can develop. Pre-service teachers need to be exposed to the "knowledge hierarchy" and to initially proceed to the second level of "conscious incompetence" in order for them to make further progress. This could be accomplished by having the develop a "personal mathematics plan" in which they identify current knowledge, areas in which they need further development, and a professional learning plan by which they will hopefully see that development to fruition. Along with this, the mathematics competency test could be seen as an indicator of development and taken on a number of occasions to enable the pre-service teachers to monitor their own progress. Perhaps a competency test could be set at increasing levels of difficulty with a minimum level needing to be passed prior to graduation.

As well, there was some inference made about antecedents of mathematics anxiety by some participants and it is suggested that pre-service teachers need to be made aware of how such antecedents can affect attitudes towards mathematics. It is recommended that the whole issue of mathematics anxiety be brought to the fore and that pre-service teachers are provided with opportunities to consider what antecedents may have had an impact on their own attitudes and how they might deal with the situation.

As noted earlier in this paper, it is important for prospective teachers to be competent in mathematics so that they are able to meet the requirements for entry to teacher education programs and if they do not, then appropriate measures need to be implemented by tertiary institutions to ensure that they graduate as competent teachers. Associated with this is the need for graduate teachers (and all teachers for that matter) to project positive attitudes towards mathematics if they are to inspire their own students to want to learn and use mathematics. It is interesting to note that one of the participants identified with that point during her interview.

\section{References}

[1] Tatto, M., Peck, R., Schwille, J., Bankov, K., Senk, S., Rodriguez, M., Ingvarson, L., Reckase, M. and Rowley, G. (2012) Policy, Practice, and Readiness to Teach Primary and Secondary Mathematics in 17 Countries: Findings from the IEA Teacher Education and Development Study in Mathematics (TEDS-M). International Association for the Evaluation of Educational Achievement (IEA), Amsterdam.

[2] Australian Institute for Teaching and School Leadership (AITSL) (2011) Accreditation of Initial Teacher Education Programs in Australia: Standards and Procedures. http://www.aitsl.edu.au/

[3] Malinsky, M., Ross, A., Pannells, T. and McJunkin, M. (2006) Math Anxiety in Pre-Service Elementary School Teachers. Education, 127, 274-279.

[4] Hurst, C. and Cooke, A. (2012) Mathematics Anxiety and Confidence: Exploring Links. The 8th International Conference in Education (ICE), Samos.

[5] Cooke, A. and Sparrow, L. (2012) Anxiety, Awareness, and Action: Mathematical Knowledge for Teaching. The 12th International Congress on Mathematical Education (ICME), Seoul, 2012.

[6] Michigan State University MSU Today (2012) Countries that Best Prepare Math Teachers Share Similarities. http://news.msu.edu/story/countries-that-best-prepare-math-teachers-share-similarities/

[7] Cavanagh, R. and Sparrow, L. (2010) Measuring Mathematics Anxiety: Constructing and Validating the Measure. The 2010 AARE International Research in Education Conference, Melbourne, 28 November-2 December 2010.

[8] Cooke, A., Cavanagh, R., Hurst, C. and Sparrow, L. (2011) Situational Effects of Mathematics Anxiety in Pre-Service Teacher Education. 2011 AARE International Research in Education Conference, Hobart. 